\title{
POSSIBLE EFFECTS AND INTER-RELATIONSHIP BETWEEN CHANGES OF ATMOSPHERIC OZONE CONCENTRATION AND GLOBAL WARMING
}

\author{
WL Sumathipala and KIA Kularatne \\ Montreal Protocol Unit, Enviconment Division, \\ Ministry of Environment and Natural Resources, Battaramulla
}

Halogenated organic compounds such as Chlorofluorocarbons (CFCs), Hydro fluorocarbons (HCFCs) and Halons are basically used as refrigerants, aerosol propellants, solvents, for fire fighting and as form blowing agents. These gases are considered as the primary cause for depletion of stratospheric ozone layer. Carbondioxids, Methane, Nitrousoxide, CFCs, HCFCs, Halons and Hydrofluorocarbons (HFCs) are categor $z: d$ as greenhouse gases and are leading to a global warming due to their heat trapping ability. According to recent researches, scientists have proven that there are both positive and negative impacts on global warming arising due to the ozone layer depletion.

Carbondioxide is the major contributor for achieving the global radiative equilibrium, which keeps the earth temperature above its black body tem perature. In the stratosphere, ozone absorbs energy from solar radiation and cools via the infrare emission. Thin ozone layer will let more ultraviolet to troposphere where ozone concentra ion will increase. Hence the increase in concentration of ozone will lead to a cooling of the troposphere by emitting infrared radiation. This cooling will lead to two opposing effects. Lower temperature will slow down the reaction rates of the ozone destroying catalytic cycles in gas phase chemistry. On the other hand, lower temperature causes the increase of probability to have more stratospheric clouds and increase the concentration of CFCs trapped in the clouds. During the springtime CFCs are release from these clouds and they will in turn enhance rapid depletion cf ozone layer.

Oxidation of methane in lower stratosphere leads to formation of water vapour and increase the possibility of polar stratospheric clouds in middle la itudes. This will help to provide activate chlorine and bromine radicals and enhanced ozone d pletion. CFCs and halons are both ozone depleting substances and greenhouse gases. Inadvertently, alternatives for ozone depleting substances such as HFCs are green house gases and as such enhance the global warming effect. 